\title{
Carbon Equivalent Fundamentals in Evaluating the Weldability of Microalloy and Low Alloy Steels
}

\author{
Munkaila Alhassan*, Yussif Bashiru \\ Department of Welding and Fabrication Engineering, Faculty of Engineering, Tamale Technical University, Tamale, Ghana \\ Email: ^munkhas@yahoo.com
}

How to cite this paper: Alhassan, M. and Bashiru, Y. (2021) Carbon Equivalent Fundamentals in Evaluating the Weldability of Microalloy and Low Alloy Steels. World Journal of Engineering and Technology, 9 , 782-792.

https://doi.org/10.4236/wjet.2021.94054

Received: August 14, 2021

Accepted: November 7, 2021

Published: November 10, 2021

Copyright ( 2021 by author(s) and Scientific Research Publishing Inc. This work is licensed under the Creative Commons Attribution International License (CC BY 4.0).

http://creativecommons.org/licenses/by/4.0/

\begin{abstract}
Understanding the weldability of steel in relation to the use of carbon equivalent is very necessary for the welding industry. The study was poised to unearth the fundamentals of carbon equivalent as applied in evaluating the weldability of steel. The study used a two-stage design approach to address the problem of carbon equivalence weldability of steel, thus, survey and experimental. Two different steels were tested to ascertain their chemical composition which could inform carbon equivalent calculation, and the results revealed microalloy and low alloy steels respectively. In subjecting the microalloy steel to carbon equivalent analyses of the AWS and IIW coefficients; revealed a value $(\mathrm{CEV})=0.11$ each, suggesting that this microalloy steel has excellent weldability; no preheating is required. A successful welding operation on this steel does not depend on preheating. Also, the average results of the low alloy steel revealed a value $(\mathrm{CEV})=0.37$ and 0.32 respectively, suggesting that this type of steel has very good weldability and may require to preheat. It is recommended that welders have a general idea about the weldability of steel with regard to carbon equivalent calculation. In addition, they should understand the chemical compositions of steels they are dealing with.
\end{abstract}

\section{Keywords}

Carbon Equivalent, Evaluation of Weldability, Microalloy Steel, Low Alloy Steel, Chemical Composition

\section{Introduction}

Carbon equivalent is an essential predictor of steel hardenability, weldability and hydrogen induced cracking [1]. However, welders do not have a basic understanding of the workings of carbon equivalent predictability of steel properties. 
Whereas few of them have a hazy idea, the majority of them have not heard of carbon equivalent before. It is no wonder most welders turn away most jobs involving low alloy steels under the pretext of the fact that "those steels are difficult to weld" and claim from experience that those metals are hard and can easily crack during or after welding. Most of these turn-away jobs are repair-related on microalloy and low alloy steels of machine parts. It is against this background this study had been conducted to investigate the level of understanding of welders within the community. In addition, introduce welders to the evaluative capability of carbon equivalent.

Carbon equivalent is a comprehensive tool used, in recent times, to predict steel properties in welding engineering [2]. Properties such as hardenability, hydrogen cracking susceptibility of steel (cold cracking) can be measured. Likewise steel strength and heat affected zone (HAZ) hardenability [3]. The concept of equivalent carbon content is applicable to ferrous materials to determine the various properties of the steel if other alloying elements, apart from carbon, are included [4]. However, carbon equivalence was initially restricted to a numerical value for a steel composition. This value explained the carbon content which would contribute to equivalence. The carbon equivalent is a measure of the tendency of the weld to form martensite on cooling and to suffer brittle fracture [1]. When the carbon equivalence is between 0.40 and 0.60 weld-preheat may be necessary. However, carbon equivalence value below 0.35 does not call for any preheating. When the carbon equivalent is above 0.60 , preheating is necessary, postheat may be necessary. The AWS states that for equivalent carbon content above $0.40 \%$ there is a potential for cracking in the heat-affected zone (HAZ) on flame cut edges and welds. Clearly, structural engineering standards rarely use $\mathrm{CE}$, but rather limit the maximum percentage of certain alloying elements. Carbon equivalence is used in welding to examine the different alloying elements affecting the hardness of the steel being welded [5]. It is pertinent to understand that hydrogen-induced cold cracking is the most common weld defect for steel. Hydrogen-induced cracking is a commonly used factor to determine the weldability of steel. Higher values of carbon and other alloying elements tend to raise the hardness of the steel and for that matter lower the weldability. Microalloy (HSLA) steels usually consist of the following alloying elements: chromium, manganese, silicon, vanadium, molybdenum, nickel and copper [5] [6]. To prevent hydrogen induced cracking in low alloy steel it is sometimes necessary to preheat [7]. Hydrogen induced cracking is also referred to as cold cracking. Cold cracking is directly proportional to an increase in carbon as well as an increase in thickness of the steel. Dearden and O'Neill [6] indicated that the susceptibility of cold cracking is not determined only by the steel's chemical composition, but also plate thickness and weld size. Simply put, the higher the carbon content the easier it is for the steel to harden; and the thicker the material the faster the cooling rate. An increase in carbon and material thickness accelerates the formation of martensite microstructure which is prone to brittle fracture. In a majority of cases, the CE method does not take into account the thickness of the base ma- 
terial. Literature informed that any time the thickness exceeds $13 \mathrm{~mm}$, preheating should be applied. The results of $\mathrm{CE}$ indicate that the lower the value the higher the weldability of the steel. However high values of CE suggest increased hardenability, therefore preheating is necessary for a successful weld. Carbon equivalent (CE) is used to determine the hardness of the steel being welded. Obviously, lower values of carbon equivalent suggest weldability of the steel in question, but those materials with high $\mathrm{CE}$ values suggest difficulty during welding. Table 1 below provides a range for $\mathrm{CE}$ and its effect on weldability and values that require preheating.

It is pertinent to inform from literature the functions of some of the elements. For example elements such as phosphorus and sulphur increase ductility, manganese increases hardness, while silicon and copper increase corrosion resistance. Nitrogen also assists in corrosion resistance. Niobium $(\mathrm{Nb})$ raises the yield strength by as much as $200 \mathrm{MPa}$ in comparison to the effect of, say, $1 \% \mathrm{Ni}$, which raises yield strength by $38 \mathrm{MPa}$. In terms of weight, microalloy steels are significantly lower in weight as compared to other materials with similar strength. This study is designed to examine the weldability of microalloy and low alloy steels via carbon equivalent calculation. Problems associated with these materials are hardness as compared to low carbon steel; the welder may be confronted with quenched effect and cracking during or after welding. At times these materials require some form of preheating before welding or possibly post-heat. The study will also determine the status of preheating of these materials. The survey was deliberately conducted to confirm welders' lack of knowledge of carbon equivalence ability to evaluate the weldability of steel and therefore bridge the gap; and the specific objectives are:

- To investigate the level of awareness of welders about carbon equivalence predictability.

- To determine, by laboratory experiment, the chemical compositions of micro-alloy and low-alloy steels.

- To evaluate the weldability of these two steels by means of carbon equivalence analysis.

\subsection{Steel Grades}

Apart from the fact that steel is produced into different types such as plain carbon

Table 1. Range of CE for weldability and preheating of steel.

\begin{tabular}{ccc}
\hline Carbon equivalent $(\mathrm{CE})$ & Weldability & Preheating \\
\hline Up to 0.35 & Excellent & Not Necessary \\
$0.36-0.40$ & Very good & Recommended \\
$0.41-0.45$ & Good & Necessary \\
$0.46-0.50$ & Fair & Necessary \\
0.51 and over & Poor & Necessary
\end{tabular}


steel, cast iron, stainless steel, etc., it is also produced into various grades, such as the API, ASTM and many more, depending on the manufacturers, chemical composition and the function for which the steel is designed to perform. Table 2 displays a typical API steel grade and code while Table 3 shows the ANFIS-II model.

\subsection{Carbon Equivalent Standards}

Calculation of carbon equivalent of steel is generally based on the additive rule with a given formula from the literature. Scholars and institutions have developed various $\mathrm{CE}$ formulas, however, the two most commonly used are those accepted by the American Welding Society (AWS), Equation (1) and the International Institute of Welding (IIW), Equation (2) as given below:

$$
\mathrm{CE}=\mathrm{C}+\frac{\mathrm{P}}{2}+\frac{\mathrm{Mn}}{6}+\frac{\mathrm{Mo}}{4}+\frac{\mathrm{Cr}+\mathrm{V}}{5}+\frac{\mathrm{Ni}}{1}
$$

where $\mathrm{CE}=$ carbon equivalent, $\mathrm{C}=$ arbon, $\mathrm{P}=$ phosphorus, $\mathrm{Mn}=$ manganese, $\mathrm{Mo}=$ molybdenum, $\mathrm{Cr}=$ chromium, $\mathrm{V}=$ vanadium and $\mathrm{Ni}=$ nickel .

Carbon Equivalent of Dearden and O'Neill used Reeve weldability tests to examine the relationship between steel's chemical composition and its maximum HAZ hardness. The end result was the proposition of the following carbon equivalent formula to express HAZ hardness.

The carbon equivalent by Dearden and O'Neill was revised slightly to the current standard of IIW (International Institute of Welding) carbon equivalent:

$$
\text { CEiiw }=\mathrm{C}+\frac{\mathrm{Mn}}{6}+\frac{\mathrm{Cu}+\mathrm{Ni}}{15}+\frac{\mathrm{Cr}+\mathrm{Mo}+\mathrm{V}}{5}
$$

where $\mathrm{CE}=$ carbon equivalent, iiw $=$ international welding society, $\mathrm{C}=$ carbon, $\mathrm{Mn}=$ manganese $\mathrm{Cu}=$ copper, $\mathrm{Ni}=$ nickel, $\mathrm{Cr}=$ chromium, $\mathrm{Mo}=$ molybdenum and $\mathrm{V}=$ vanadium

Table 2. API microalloyed steel grade range.

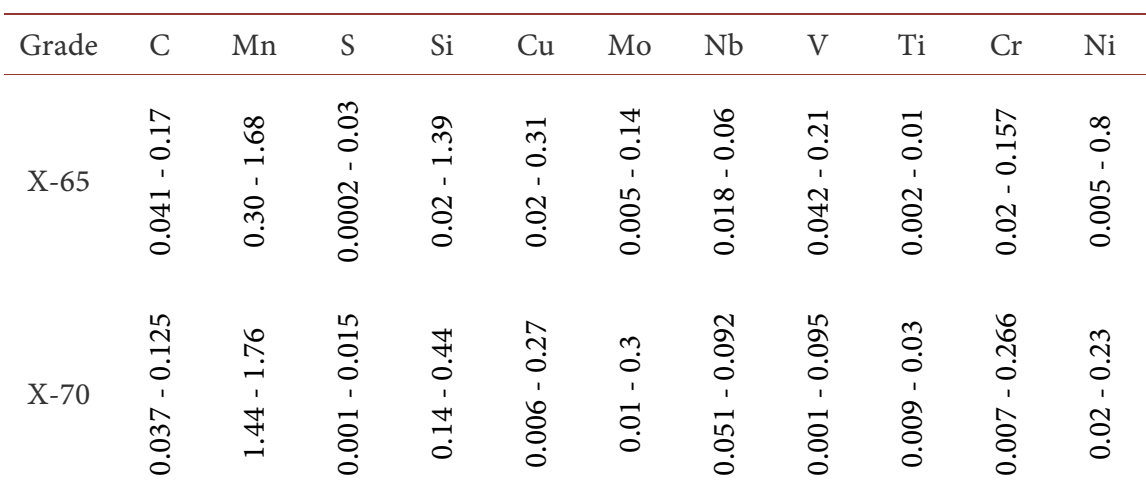

Table 3. ANFIS-II model for macroalloy.

\begin{tabular}{ccccccccccc}
\hline Grade & $\mathrm{C}$ & $\mathrm{Nb}$ & $\mathrm{Mn}$ & $\mathrm{Mo}$ & $\mathrm{Ti}$ & $\mathrm{N}$ & $\mathrm{P}$ & $\mathrm{S}$ & $\mathrm{Si}$ & $\mathrm{Al}$ \\
\hline 0.062 & 1.24 & 0.063 & 0.008 & 0.002 & 0.007 & 0.007 & 0.004 & 0.051 & 0.04 \\
& 0.062 & 1.24 & 0.063 & 0.008 & 0.002 & 0.007 & 0.007 & 0.004 & 0.051 & 0.04 \\
\hline
\end{tabular}


The equation usually adopted by the International Institute for Welding is the first equation. However in analysing low carbon steel the $\mathrm{P}_{\mathrm{cm}}$ and CEM equations are mosly employed. In addition, where the carbon content of given steel is less than 0.11 by wt.\%, the second PCM equation is used for modern steels used in pipeline manufacture. However other formulas have been developed; the Japanese Welding Engineering Society adopted the critical metal parameter $(\mathrm{Pcm})$ for weld cracking which is based on the work from Ito and Bessyo. Also, the CEq formula was devised by Düren with characteristics: Both the $\mathrm{P}_{\mathrm{cm}}$ and the $\mathrm{CEq}$ formulae were developed for low carbon steels for which the $\mathrm{CE}_{\text {IIW }}$ is less suitable. $\mathrm{P}_{\mathrm{cm}}$ is generally used for modern steels and typically used for pipeline manufacture, where carbon contents are no more than $\sim 0.11 \mathrm{wt} . \%[8]$.

$$
\mathrm{P}_{\mathrm{cm}}=\mathrm{C} \%+\frac{\mathrm{Si} \%}{30}+\frac{\mathrm{Mn} \%+\mathrm{Cu} \%+\mathrm{Cr} \%}{20}+\frac{\mathrm{Ni} \%}{60}+\frac{\mathrm{Mo} \%}{15}+\frac{\mathrm{V} \%}{10}+5 \mathrm{~B}
$$

where $\mathrm{P}_{\mathrm{cm}}=$ critical metal parameter, $\mathrm{C}=$ carbon, $\mathrm{Si}=$ silicon, $\mathrm{Mn}=$ manganese, $\mathrm{Cu}=$ copper, $\mathrm{Cr}=$ chromium, $\mathrm{Ni}=$ nickel, $\mathrm{Mo}=$ molybdenum, $\mathrm{V}=$ vanadium and $\mathrm{B}=$ boron.

\section{Materials and Methods}

This study employed two-stage design approach to addressing the problem of carbon equivalence weldability of steel. The study considered both survey and experimental approaches, the first stage dealt with the use of questionnaire survey to investigate the level of understanding of welders on the use of carbon equivalent to predict steel wedability. The second stage involved a laboratory test to ascertain the chemical compositions of steel which could inform carbon equivalent calculations for the evaluation of steel weldability.

\subsection{Methods}

The survey was carefully conducted to verify welders level of understanding of carbon equivalence. The purposive sampling technique had been used in this study to select the participants. This is a deliberate choice of participants for the experiences they possess in welding and fabrication. This involves identifying and selecting individuals or groups of individuals that are especially knowledgeable about or experienced with a phenomenon of interest [9]. The purposive sampling is a nonrandom (non-probability) technique that does not need underlying theories or a set number of participants [10]. The researcher decided what needs to be known and for that matter set out to find people who could and were willing to provide the information by virtue of knowledge or experience. Survey questionnaires of 35 cases were then administered to participants. This sample was considered representative over the population as such remained valid over the realm it represents, providing both internal and external validity. The questionnaire was made up of seven (7) items in the form of 5-point rating scale. The rating scale consisted of Highly Impracticable $(\mathrm{HI}=1)$, Impracticable $(\mathrm{I}=2)$, Neither Impracticable nor Practicable (NIP $=3)$, Practicable $(\mathrm{P}=4)$ and 
Highly Practicable $(\mathrm{HP}=5)$. Data gathered were entered into SPSS for analysis. However, the last item, CEW7 took a different form, thus Strongly Disagree (SD $=1)$, Disagree $(\mathrm{D}=2)$, Neither Agree nor Disagree $(\mathrm{NAD}=3)$, Agree $(\mathrm{A}=4)$, Strongly Agree $(\mathrm{SA}=5)$.

\subsection{Materials}

In order to make $\mathrm{CE}$ calculation possible there was the need to ascertain the chemical compositions of the two different steels with which a repair welder had to exercise more professionaism in welding. Some welders consider these materials a bit more difficult when compared with the welding of low-carbon steel. The two samples were then prepared in the form of squre prism as seen in Figure 1; with a squre geometry of $15 \mathrm{~mm}$, and a length of $150 \mathrm{~mm}$, see Figure 1 . These samples were ground and polished to remove oxides and notches from the surfaces. The experiment was then performed using mass spectrometer at the Tema Steel Company Ltd., Ghana. The tests were conducted in two runs each, revealing different outputs and the average results were established for each sample.

After the experiment had been conducted, the materials were identified as microalloy and low alloy steels respectively and the results had been displayed in Table 4. Each steel was run twice and the average results were considered using AWS and IIW coefficients as seen in Table 5.

Table 5 outlines the various formulas developed by different organisations, institutions and authors for convenience purposes in calculating the CE of steel. Table 5 also presents the coefficients of each formula. This has been instrumental in determining the outcome of this current study with the application of international institute of welding (IIW) and American welding society (AWS) standatds.

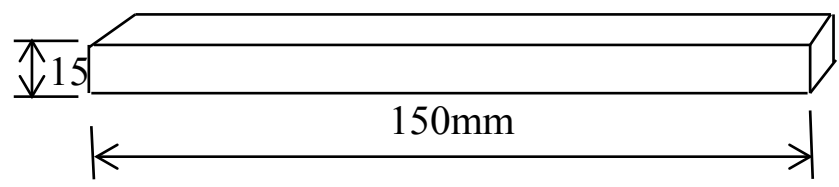

Figure 1. Steel Specimen.

Table 4. Experimental results revealing microalloy and low alloy steels.

\begin{tabular}{ccccccccc}
\hline Microalloy steel & $\mathrm{C}$ & $\mathrm{Si}$ & $\mathrm{V}$ & $\mathrm{Mn}$ & $\mathrm{Cr}$ & $\mathrm{Mo}$ & $\mathrm{Cu}$ & $\mathrm{Ni}$ \\
\hline Run1 & 0.060 & 0.32 & 0.03 & 0.060 & 0.024 & 0.055 & 0.018 & 0.011 \\
Run2 & 0.070 & 0.33 & 0.04 & 0.080 & 0.024 & 0.053 & 0.019 & 0.010 \\
Total Av. & 0.060 & 0.32 & 0.035 & 0.140 & 0.024 & 0.054 & 0.037 & 0.010 \\
\hline Low alloy steel & $\mathrm{C}$ & $\mathrm{Cu}$ & $\mathrm{Si}$ & $\mathrm{Mn}$ & $\mathrm{Ni}$ & $\mathrm{Cr}$ & $\mathrm{Mo}$ & $\mathrm{V}$ \\
\hline Run1 & 0.21 & 0.02 & 0.23 & 0.21 & 0.15 & 0.11 & 0.15 & 0.02 \\
Run2 & 0.22 & 0.02 & 0.12 & 0.23 & 0.13 & 0.12 & 0.14 & 0.02 \\
Average & 0.21 & 0.02 & 0.22 & 0.22 & 0.14 & 0.12 & 0.14 & 0.02 \\
\hline
\end{tabular}


Table 5. Coefficients (backward) in indices of carbon equivalent proposed by various authors.

\begin{tabular}{cccccccccccc}
\hline No & Author & $\mathrm{C}$ & $\mathrm{Mn}$ & $\mathrm{Si}$ & $\mathrm{Cu}$ & $\mathrm{Ni}$ & $\mathrm{Cr}$ & $\mathrm{Mo}$ & $\mathrm{Nb}$ & $\mathrm{V}$ & $\mathrm{B}$ \\
\hline 1 & IIW & 1 & 6 & 24 & 5 & 5 & 15 & 5 & - & 15 & - \\
2 & AWS & 1 & 6 & 38 & - & 1.8 & 12 & 4 & - & 9.1 & - \\
3 & Ito Bessyo & 1 & 20 & 30 & 20 & 60 & 20 & 15 & - & 10 & $1 / 5$ \\
4 & Yurioka (8) & 1 & 6 & 24 & 13 & 40 & 6 & 4 & 5 & 5 & $1 / 10$ \\
5 & Suzuki (14) & 1 & 6 & 24 & 15 & 15 & 5 & 5 & & 3 & $1 / 15$ \\
\hline
\end{tabular}

\section{Survey Results}

The survey was deliberately conducted to confirm welders' lack of knowledge of carbon equivalence, which has the ability to evaluate the weldability of steel. Table 6 indicates that after the close of this survey a total of 35 responses were analysed. The academic qualifications for welders were predominantly national proficiency holders (45.7\%), suggesting that those with national proficiency certificates were in the majority in the welding industry, followed by those with basic education and then those without formal education, (17.1\%) each. However, those with tertiary education such as bachelor of degree (2.9\%) and higher national diploma (5.7\%) were in the minority, suggesting that the welding industry is interested in skill labour more than academic pursuit. Basically, welders between the ages of 26 - 30 were dominant in the industry, representing $37.1 \%$, followed by 31 - 35 (22.9\%). This depicts the youthful nature of the industry. Those aged 46 and above were few $(2.5 \%)$, suggesting that the aged were gradually retiring from the profession.

Demographic characteristics of the respondents were essential for this study in order to determine their experience. This included level of education, age and number of years of working. When considering how long the respondent had been working in the welding industry, those who have worked from $11-15$ years (28.6\%), and were the majority. They were followed by those with $21-25$ years (22.9\%), and then followed by $6-10$ and 16 - 20 years' work experience (20.0\%) each. Those who had worked from $1-5$ years were less (8.6\%), indicating that the purposive sampling did not consider so much the inexperienced and those with short service experience.

The descriptive statistics in Table 7 displays the outcome of participants about their general understanding of steel weldability. CEW1 was to test welders basic understanding as to whether steel can be lab-tested to establish its chemical composition, and out of $\mathrm{N}=35,15$ see that to be impracticable, 6 also see that to be highly impracticable, giving an aggregate percentage of $60 \%$. Suggesting that $60 \%$ of welders within the community are not aware of the fact that experimental test can be conducted on steel to reveal the chemical composition. CEW2 was to measure welders basic understanding as to whether the hardenability of steel can be predicted by carbon equivalent, and out of $\mathrm{N}=35,15$ view that to be 
Table 6. Demographic characteristics of the respondents.

\begin{tabular}{lcc}
\hline Highest Educational Qualification & Count & Percentage \\
Bachelor's Degree & 1 & 2.9 \\
HND/Diploma & 2 & 5.7 \\
Secondary/Technical & 4 & 11.4 \\
National Proficiency & 16 & 45.7 \\
Basic Education & 6 & 17.1 \\
Absence of Formal Education & 6 & 17.1 \\
\hline Age Group & & \\
$21-25$ & 3 & 8.6 \\
$26-30$ & 13 & 37.1 \\
$31-35$ & 8 & 22.9 \\
$36-40$ & 4 & 11.4 \\
$41-45$ & 6 & 17.1 \\
46 and above & 1 & 2.9 \\
\hline Number of Years of Working in the Industry & & \\
1 - 5 Years & & \\
6 - 10 Years & 3 & 8.6 \\
$11-15$ Years & 7 & 20.0 \\
16 - 20 Years & 10 & 28.6 \\
$21-25$ Years & 7 & 20.0 \\
\hline
\end{tabular}

Table 7. Participants' response on general understanding of steel weldability.

\begin{tabular}{lcccccc}
\hline General Understanding of Weldability & $\mathbf{1}$ & $\mathbf{2}$ & $\mathbf{3}$ & $\mathbf{4}$ & $\mathbf{5}$ & Total \\
\hline $\begin{array}{l}\text { CEW1. Steel can be lab-tested to ascertain } \\
\text { its chemical Composition }\end{array}$ & 6 & 15 & 1 & 7 & 6 & 35 \\
CEW3. Steel hardenability can be examine & 9 & 15 & 2 & 8 & 1 & 35 \\
$\begin{array}{l}\text { from carbon } \\
\text { f.1\% }\end{array}$ & $25.7 \%$ & $42.9 \%$ & $5.7 \%$ & $22.9 \%$ & $2.9 \%$ & $100 \%$ \\
CEW2. Steel weldability can be evaluated & 6 & 19 & 4 & 6 & 0 & 35 \\
from carbon Equivalence & $17.1 \%$ & $53.4 \%$ & $11.4 \%$ & $17.0 \%$ & $0.0 \%$ & $100 \%$ \\
CEW4. Welders understand the use of CE & 6 & 18 & 1 & 10 & 0 & 35 \\
to examine steel Weldability & $17.1 \%$ & $51.4 \%$ & $2.90 \%$ & $28.6 \%$ & $0.0 \%$ & $100 \%$ \\
CEW5. Welders understand the use of & 6 & 17 & 1 & 11 & 0 & 35 \\
$\begin{array}{l}\text { pre/post-heat treatment on steel } \\
\text { CEW6. Welders identify hardenable steel }\end{array}$ & $17.1 \%$ & $48.6 \%$ & $2.90 \%$ & $31.4 \%$ & $0.0 \%$ & $100 \%$ \\
$\begin{array}{l}\text { CEm non-hardenable ones } \\
\text { from }\end{array}$ & $25.7 \%$ & $54.3 \%$ & $2.9 \%$ & $17.1 \%$ & $0.0 \%$ & $100 \%$ \\
$\begin{array}{l}\text { CEW7. Welders desire to understand CE } \\
\text { calculations applied to welding }\end{array}$ & 2 & 3 & 1 & 13 & 16 & 35 \\
\hline
\end{tabular}

impracticable, 9 also view that to be highly impracticable, giving an aggregate percentage of $68.6 \%$. This therefore suggests that $68.6 \%$ of welders within the community are not aware of the fact that carbon equivalent calculation can be used to predict the hardenability of steel. CEW3 was to evaluate welders basic understanding as to whether the weldability of steel can be predicted by carbon 
equivalent, and out of $\mathrm{N}=35,19$ view that to be impracticable, 6 also view that to be highly impracticable, giving an aggregate percentage of $70.5 \%$, suggesting that $70.5 \%$ of welders within the community are not aware of the fact that carbon equivalent calculation can be used to predict the weldability of steel. Therefore CEW4 confirms the fact that welders have no idea of the fundamentals of carbon equivalent for evaluating the weldability of steel, this attracted an aggregate percentage of $68.5 \%$. CEW5 was to examine welders basic understanding of pre-heat and post-heat treatment in the course of welding, and out of $\mathrm{N}=35,17$ view that to be impracticable, 6 also view that to be highly impracticable, giving an aggregate percentage of $65.7 \%$, suggesting that $65.7 \%$ of welders within the community had no basic understanding of welding heat treatment processes. CEW6 was to examine welders basic understanding as to whether they can distinguish hardenable from non-hardenable steel, and out of $\mathrm{N}=35,19$ perceived that to be impracticable, 9 also perceived that to be highly impracticable, giving an aggregate percentage of $80.0 \%$, suggesting that $80.0 \%$ of welders within the community cannot distinguish hardenable from non-hardenable steel. CEW7 was to enquire from welders if they have the desire to learn the fundamentals of carbon equivalent as applied in evaluating the weldability of steel, and out of $\mathrm{N}=$ 35,13 rated agreed, 16 also rated strongly agreed, giving an aggregate percentage of $82.8 \%$, suggesting that $82.8 \%$ of welders within the community agreed to have general understanding of fundamentals of carbon equivalent prediction to steel weldability. It is against this background that the study went further to lay the fundamentals of carbon equivalent and its calculation.

\section{Experimental Results}

Table 8 displays the results of the experiment. The steel was run twice and the average results were recorded as seen in Table 1. Subjecting this to carbon equivalent analyses of the AWS coefficients and IIW; revealed a value $(\mathrm{CEV})=$ 0.11 each, suggesting that this microalloy steel has excellent weldability. A successful welding operation on this steel does not depend on preheating neither it depends on post-heating.

Table 9 displays the results of low alloy steel run twice to ascertain the chemical composition, and the results were recorded as seen. Subjecting the average

Table 8. Summary of results based on AWS and IIW (Steel A).

\begin{tabular}{ccccccccc}
\hline Microalloy steel & C & Si & V & Mn & Cr & Mo & Cu & Ni \\
\hline Run1 & 0.060 & 0.32 & 0.03 & 0.060 & 0.024 & 0.055 & 0.018 & 0.011 \\
Run2 & 0.070 & 0.33 & 0.04 & 0.080 & 0.024 & 0.053 & 0.019 & 0.010 \\
Total Av. & 0.060 & 0.32 & 0.035 & 0.140 & 0.024 & 0.054 & 0.037 & 0.010 \\
\hline Heat No. & CEEq. & CEV & & Weldability & Preheating & Post-heat \\
\hline Average & AWS & 0.11 & & Excellent & Not at all & Not at all \\
Average & IIW & 0.11 & & Excellent & Not at all & Not at all \\
\hline
\end{tabular}


Table 9. Summary of results based on AWS and IIW (Steel B).

\begin{tabular}{ccccccccc}
\hline Low alloy steel & $\mathrm{C}$ & $\mathrm{Cu}$ & $\mathrm{Si}$ & $\mathrm{Mn}$ & $\mathrm{Ni}$ & $\mathrm{Cr}$ & $\mathrm{Mo}$ & $\mathrm{V}$ \\
\hline Run1 & 0.21 & 0.02 & 0.23 & 0.21 & 0.15 & 0.11 & 0.15 & 0.02 \\
Run2 & 0.22 & 0.02 & 0.12 & 0.23 & 0.13 & 0.12 & 0.14 & 0.02 \\
Average & 0.21 & 0.02 & 0.22 & 0.22 & 0.14 & 0.12 & 0.14 & 0.02 \\
\hline Heat No. & CEEq. & CEV & Weldability & Preheating & Post-heat \\
Average & AWS & 0.37 & Very good & Not necessary & Not necessary \\
Average & IIW & 0.32 & Excellent & Not at all & \multicolumn{2}{c}{ Not at all } \\
\hline
\end{tabular}

results to analysis using the AWS and IIW coefficients; revealed a value $(\mathrm{CEV})=$ 0.37 and 0.32 respectively, suggesting that this type of steel has very good weldability. It is also recommended that the steel be preheated before welding, however post-heating is not necessary.

Evidently, carbon equivalence values between 0.40 and 0.60 weld-preheat may be necessary. Preheating is therefore necessary when the carbon equivalent is above 0.60 , likewise post-heat. The AWS states that for equivalent carbon content above $0.40 \%$ there is a potential for cracking in the heat-affected zone (HAZ) on flame cut edges and welds.

\section{Conclusions}

The general understanding of weldability in relation to the use of carbon equivalent is very poor among welders. As a result, this study had taken the pains to lay down the fundamentals of carbon equivalent as applied in evaluating the weldability of steel. Two different samples were tested to ascertain their chemical compositions and after which $\mathrm{CE}$ was applied to determine their carbon equivalent values.

The test revealed microalloy and low alloy steels identifiable on the basis of their chemical contents and percentages. In terms of percentage, microalloy steels have lower carbon content than low alloy steels. Likewise, other alloying elements of microalloy steel are relatively lower than that of low alloy steel. Microalloy steels have carbon content less than $0.10 \%$ and all the same, achieve strength by copper precipitation and therefore obtain a good combination of strength and weldability [7]. The first and second run of microalloy steel of this current study revealed 0.06 and 0.07 by weight while the low alloy steel revealed 0.21 and 0.22 by weight. Table 4 presents the percentages of the various chemical elements of the two steels. Subjecting the microalloy steel to carbon equivalent analyses of the AWS coefficients and IIW; revealed a value $(\mathrm{CEV})=0.11$ each, suggesting that this microalloy steel has excellent weldability. A successful welding operation on this steel does not depend on preheating. Also, the average results of the low alloy steel revealed a value $(\mathrm{CEV})=0.37$ and 0.32 respectively, suggesting that this type of steel has very good weldability. However, it is recommended that the steel be preheated before welding, however, post-heat is not 
necessary. Basically, carbon equivalence values between 0.40 and 0.60 weldpreheat may be necessary. However, carbon equivalent above 0.60 , both preheating and post-heat are necessary. The AWS states that for equivalent carbon content above $0.40 \%$ there is a potential for cracking in the heat-affected zone (HAZ) on flame cut edges and welds. It is recommended that welders have a general idea about the hardenability of steel through CE values which in turn influences the weldability of the steel. Further welders should understand the chemical compositions in order to identify the type of steel they are dealing with.

\section{Conflicts of Interest}

The authors declare no conflicts of interest regarding the publication of this paper.

\section{References}

[1] Kasuya, T. and Yurioka, N. (1991) Carbon Equivalent and Multiplying Factor for Hardenability of Steel. The 72nd Annual AWS Meeting, Detroit, Mich, 15-19 April 1991.

[2] Kostin, V.A. (2012) Mathematical Formulation of Carbon Equivalent as a Criterion for Evaluation of Steel Weldability. The Paton Welding Journal.

[3] Wang, W. (2016) The Great Minds of Carbon Equivalent Part-IV: Future Trends on Carbon Equivalent Research. Materials Group, EWI.

[4] Ito, I. and Bessyo, K. (1968) Cracking Parameter of High Strength Steels Related to HAZ Cracking. Journal of the Japan Welding Society, 9, 983-991.

[5] Reeve, L. (1939) Metallurgy of Ferrous Welding, Note on Cambridge Welding Conference. Transactions of the Institute of Welding, 2, 7-18.

[6] Dearden, J. and O'Neill, H. (1940) A Guide to the Selection and Welding of Low Alloy Strucutural. Steels, Transactions of the Institute of Welding, 3, 203-214.

[7] Radmj, D.S. (1991) Carbon Equivalence and Weldability of Microalloyed Steels SSC357. Ship Structure Committee.

[8] Bailey, N. (1994) Weldability of Ferritic Steels. Abington Publishing, Abington. https://doi.org/10.1533/9781845698935

[9] Cresswell, J.W., and Plano Clark, V.L. (2011) Designing and Conducting Mixed Method Research. 2nd Edition, Sage, Thousand Oaks, CA.

[10] Bernard, H.R. (2002) Research Methods in Anthropology: Qualitative and Quantitative Approaches. 3rd Edition, Alta Mira Press, Walnut Creek, CA. 